\title{
Por uma ética do recolhimento: um diálogo entre E. Levinas e A. Badiou
}

\author{
An ethic of retreatment: a dialogue between E. Levinas and A. Badiou
}

\section{Danilo Mendes*}

Resumo: Nesse artigo articulamos um diálogo entre E. Levinas e A. Badiou em torno da possibilidade de uma ética na conjuntura pandêmica global. Apresentamos as propostas levinasianas de uma ética do rosto e uma ética do acolhimento analisando sua impossibilidade diante da necessidade de máscaras e do isolamento. Em seguida, verificamos a hipótese de Badiou acerca de uma ética das verdades, argumentando como, diante do acontecimento coronavírus, ela se desenvolve em uma ética do recolhimento. Assim, a ética do recolhimento se torna adequada para a situação de pandemia porque mantém a fidelidade à verdade do acontecimento e possibilita a acessibilidade posterior ao rosto e ao acolhimento.

Palavras-chave: Etica, Levinas; Badiou; Recolhimento; Coronavírus

Abstract: In this paper we articulate a dialogue between E. Levinas and A. Baidou about the possibility of an ethic on today's global pandemic conjuncture. We present Levinas' proposal of an ethic of the face and an ethic of welcoming analyzing their impossibility against the necessity of masks and isolation. Then, we verify Badiou's hypothesis about an ethic of the truths, arguing how, before the event coronavirus, it develops itself in an ethic of retreatment. Thus, the ethic of retreatment becomes adequate to the pandemic situation for it is faithful to the event's truth and it enables the posterior accessibility to the face and the welcoming.

Keywords: Ethics; Levinas; Badiou; Retreatment; Coronavirus

\section{Introdução}

Dentre os diversos pensadores que se propuseram, de dentro do olho do furacão, falar sobre a crise humanitária provocada pela pandemia do novo coronavírus, chamamos atenção a Giorgio Agamben. Filósofo de um dos países que mais tem sofrido com essa situação, desde o início da quarentena italiana ele publicou mais de sete textos. Em um deles, intitulado Distanziamento sociale ${ }^{1}$, Agamben defende que, apesar de provavelmente ser um eufemismo para tratar do confinamento, falar em distanciamento social pode ser maléfico e perigoso porque uma sociedade fundada sobre essa relação não é humana e politicamente viável. Sua conclusão é que surge na sociedade uma massa baseada nessa relação e que tem como principal característica a passividade frente à política. Embora sua análise não nos seja primordial, interessa-nos um fato que permanece nas entrelinhas de seu texto: há de se repensar a ética e a política diante das mudanças causadas pela pandemia e pelo confinamento. Embora o distanciamento das relações sociais não seja efetivamente necessário (via tecnologia), o isolamento individual o é, e essa grande mudança na vida cotidiana indica que também é preciso repensar a ética.

Jean Luc Nancy, por sua vez, sublinha o caráter comunitário da pandemia em Communovirus:

${ }^{1}$ AGAMBEN, Distanziamento Sociale.

*Doutorando em Ciência da Religião na Universidade Federal de Juiz de Fora, Juiz de Fora, MG, com bolsa CAPES. E-mail: danilo.smendes@hotmail.com ORCID: https://orcid.org/oooo-0002-2810-099X 
De fato, o vírus nos comuniza. Ele essencialmente nos põe em pé de igualdade, juntando-nos na necessidade de o enfrentarmos conjuntamente. Que isso envolva o isolamento de cada um de nós é simplesmente um modo paradoxal de experimentarmos nossa comunidade ${ }^{2}$.

Esse caráter paradoxal apontado por Nancy, mais do que simplesmente acenar para uma saída da crise pandêmica através da solidariedade comunitária no isolamento, expõe a impossibilidade da ética do rosto e do acolhimento de E. Levinas. Em um tempo onde não se deve sair de casa nem receber outros em casa, como apelar a uma ética do acolhimento? Ou como fazê-lo com a ética do rosto se quando, de fato, encontramos o outro estamos de máscaras? Por isso, é preciso desconstruir a ética do rosto e do acolhimento, provisoriamente ou não, em favor de uma ética das verdades e do recolhimento. Nossa proposta, aqui, é justamente apresentar alternativas éticas que contemplem o mundo interno do isolamento. Para além de mero recurso retórico, pretendemos articular modalidades que respondam à suspensão da vida comunitária preparando o ser humano, todavia, para sua volta. Seguimos, portanto, em duas etapas: 1) desvelando a impossibilidade da ética do rosto e do acolhimento em E. Levinas; e 2) traçando uma ética das verdades em A. Badiou, que se encerra em uma ética do recolhimento.

\section{O fim da ética do rosto e do acolhimento}

Tratar de uma ética do rosto remete ao pensamento de Levinas. A questão é central em seu pensamento, a ponto de afirmar que "a ética, para além da visão e da certeza, desenha a estrutura da exterioridade como tal. A moralidade não é um ramo da filosofia, mas a filosofia primeira" 3 . Nesse sentido, o pensamento da ética toma o lugar de ontologia que a metafísica ocupava, uma vez que ela mesma constitui a exterioridade humana. A ética mesma é não-ontológica, mas manifesta-se nessa linguagem. Por isso, ela não pode ser relegada a segundo plano, mas deve ocupar o centro da discussão filosófica. Essa virada, que só se enuncia no fim de Totalidade e infinito, sua grande obra, revela o caráter fundamental do pensamento da alteridade que é levado a termo, por Levinas, sobretudo na noção de rosto do Outro.

Antes de chegarmos à questão do rosto, é preciso que pensemos a causa que levou Levinas a realizar essa virada da metafísica à ética, a saber, a redução do Outro ao Mesmo. Na fenomenologia hegeliana, por exemplo, "a diferença não é uma diferença, o eu, como outro, não é um 'Outro"' 4 . Na medida em que o outro é somente um idêntico a mim fora de mim, ele não é um Outro. Assim como Hegel, para Levinas, a tradição filosófica ocidental sempre considerou eticamente o outro como um igual a mim, isto é, um mesmo.

O Outro de Levinas, portanto, não pode se constituir a partir de um Mesmo de mim, mas somente como um totalmente outro:

O Outro metafísico é outro de uma alteridade que não é formal, de uma alteridade que não é o simples inverso da identidade, nem de uma alteridade feita de resistência ao Mesmo, mas de uma alteridade anterior a toda iniciativa, a todo imperialismo do Mesmo; outro de uma alteridade que constitui o próprio conteúdo do Outro; outro de uma alteridade que não

\footnotetext{
${ }^{2}$ NANCY, Communovirus.

${ }^{3}$ LEVINAS, Totalidade e infinito, 284.

${ }_{4}^{4}$ LEVINAS, Totalidade e infinito, 24.
} 
limita o Mesmo, porque nesse caso o Outro não seria rigorosamente o Outro: pela comunidade da fronteira, seria, dentro do sistema, ainda o Mesmo5.

Desse modo, o Outro que Levinas busca é aquele que resiste ao imperialismo do Mesmo. Essa questão pode, também, ser pensada nos termos de Heidegger entre identidade e diferença ${ }^{6}$ : na medida em que reduz o Outro ao Mesmo, a tradição filosófica pretere a diferença em relação à identidade. A ética, no sentido levinasiano é, então, "esta impugnação da minha espontaneidade pela presença de Outrem. A estranheza de Outrem - a sua irredutibilidade a Mim [...] - realiza-se precisamente como um pôr em questão da minha espontaneidade, como ética"7. O Outro, portanto, é precisamente aquele que me é estranho, que foge completamente a mim. A originalidade de Levinas em relação à tradição anterior é trazer para dentro do pensamento ético a diferença enquanto tal sem reduzi-la ao Mesmo ou à identidade ${ }^{8}$. Essa estranheza se revela no Outro a partir de algo específico, o rosto:

O modo como o Outro se apresenta, ultrapassando a ideia do Outro em mim, chamamo-lo, de facto, rosto. [...] O rosto de Outrem destrói em cada instante e ultrapassa a imagem plástica que ele me deixa, a ideia à minha medida e à medida do seu ideatum - ideia adequada ${ }^{9}$.

Esse traço epifânico que se apresenta como Outro, portanto, é visível no rosto, um rosto que impõe a ética e a responsabilidade por meio de sua violência ${ }^{10}$. A ideia do rosto do Outro que nunca é totalmente acessível e, também, por isso, irredutível ao Mesmo evoca a noção de infinito. Infinito não porque ilimitado, mas porque infinitamente diferente do eu que se põe diante dele. Há, assim, não só uma alteridade, mas uma santidade a ser reconhecida no rosto do outro ${ }^{11}$. Nesse rosto existe, para Levinas, a ética pré-formal, antes da própria ética, que estabelece mandamentos como o "não matarás".

Todavia, hoje o rosto se mostra inacessível. Não apenas porque infinito e totalmente outro, mas porque coberto. Em meio à pandemia do novo coronavírus, não é possível identificar o Outro por seu rosto, mas somente pela máscara. A máscara, todavia, não sugere alteridade alguma nem representa a efetividade do Outro em si. Máscaras são impessoais, produzidas em série e uniformizadas. Elas acabam por reduzir o Outro ao mesmo, o humano ao simplesmente mascarado. O Outro perde sua face ao usar a máscara. Ou antes, o eu perde seu Outro quando de máscara. Isso não apenas impossibilita uma ética do rosto como também nega a radical diferença do Outro em relação a mim. Não há responsabilidade alguma que o mascarado possa me impor.

Do mesmo modo uma ética do acolhimento se torna impossível. A leitura derriadiana de Levinas, aqui, nos convém. Para Derrida, o acolhimento é a base da hospitalidade, noção que é central no pensamento ético da desconstrução. Na mesma medida em que o rosto do Outro me impõe uma responsabilidade ética, a hospitalidade se impõe nesse encontro. $\mathrm{O}$

\footnotetext{
5 LEVINAS, Totalidade e infinito, 26.

${ }^{6}$ HEIDEGGER, Que é isto, a filosofia? : Identidade e diferença, p. 38-53.

7 LEVINAS, Totalidade e infinito, 30.

8 Podemos pensar como exemplo no imperativo categórico kantiano que, por definição, é impessoal e baseado na identidade pressuposta da subjetividade da mente.

9 LEVINAS, Totalidade e infinito, 37-38.

${ }^{10}$ Sobre esse tema, ver LEVINAS, Violência do rosto. Nessa entrevista, o autor diz: "Tenho descrito sempre o rosto do próximo como portador de uma ordem, que impõe ao eu, diante do outro, uma responsabilidade gratuita - e inalienável, como se o eu fosse escolhido e único - e o outro homem é absolutamente outro, isto é, ainda incomparável e, assim, único” (LEVINAS, Violência do rosto, 28).

${ }^{11}$ LEVINAS, Violência do rosto, 40.
} 
acolhimento, nesse sentido, faz parte daqueles princípios não originários que são prééticos ${ }^{12}$. Ao comentar Levinas, diz Derrida:

O acolhimento determina o 'receber', a receptividade do receber como relação ética. [...] Esse receber, termo aqui sublinhado e proposto como sinônimo de acolher, só recebe na medida - uma medida desmedida - em que ele recebe para além da capacidade do $\mathrm{eu}^{13}$.

Semelhantemente à questão do rosto, uma ética do acolhimento se torna impossível no momento em que a violência do vírus se instaura imperativamente proibindo o acolhimento e a hospitalidade. Não se pode receber o Outro em nossa própria habitação. $\mathrm{O}$ risco da infecção impossibilita a ética do acolhimento radical. Uma vez que o Outro só pode ser Outro diante de um Eu, esse deve ser mantido íntegro e, nesse caso, saudável para que qualquer relação ética se instaure. Nesse sentido, tanto a ética do rosto quanto a do acolhimento se tornam, mais do que ineficientes, impossíveis diante da imposição do isolamento. Tal afirmação não indica o esgotamento total do paradigma ético de Levinas, mas aponta seus limites nessa situação.

\section{Uma ética das verdades}

Uma importante crítica ao modelo ético de Levinas e Derrida foi realizada pelo, também baseado na França, Alain Badiou. Em Ethics, ele aproxima esses autores de uma perspectiva niilista e, então, propõe uma ética das verdades baseada, sobretudo, em sua ideia de evento ${ }^{14}$. Badiou afirma que o radicalismo ético da diferença e do outro não começa com Kant, como se afirma a partir da razão prática, mas no próprio Levinas. Essa ética poderia ser reduzida ao reconhecimento do outro por meio da tolerância, um discurso que, para Badiou, não possui valor de verdade algum nem força ${ }^{15}$. Isso porque, para ele, não há nada que comprove o real motivo da devoção pelo Outro. Só se pode basear essa devoção no apelo a um princípio absoluto de alteridade: Deus. Na medida em que Levinas apela para um axioma religioso, ele não apenas submete a filosofia à teologia, mas anula a filosofia mesma $^{16}$.

O problema com esse apelo, para Badiou, não é propriamente a religião, mas a submissão do pensamento a ela. Ao fazê-lo, a ética levinasiana se torna incoerente, porque o pensamento da identidade ocidental implica um multiculturalismo que só reconhece o Outro na medida em que ele aceita as bases de minha tolerância. Nesse sentido, a ética do Outro recai no Mesmo. Na medida em que a ética, por fim, está ligada a um Outro que inexiste, a ética pura é impossível ${ }^{17}$. Para além disso, a ética, para Badiou, se situa entre duas pulsões: o conservadorismo, em nome de uma cultura ocidental, e a morte, decidindo sobre questões bioéticas. Diz Badiou: "É por isso que a ética seria melhor nomeada como [...] um niilismo presunçoso"18.

\footnotetext{
${ }^{12}$ Nas palavras de Derrida, ele é a “origem an-árquica da ética” (DERRIDA, Adeus a Emmanuel Levinas ,6o).

13 DERRIDA, Adeus a Emmanuel Levinas , 43.

${ }^{14}$ No fim de sua obra, Badiou apresenta como as éticas contemporâneas se sustentam a partir de uma noção específica de mal que, para ele, é demasiadamente dependente das tradições religiosas ocidentais. Embora muito interessante, não nos cabe, aqui, uma incursão nessa questão.

15 BADIOU, Ethics, 20.

${ }^{16}$ BADIOU, Ethics, 22-25.

${ }^{17}$ BADIOU, Ethics, 28. Para ele uma ética é possível se acompanhada de um de. Por exemplo: ética da política, ética da filosofia, ética da medicina etc.

${ }^{18}$ BADIOU, Ethics, 38.
} 
A proposta de Badiou de uma ética das verdades não se constrói no sentido de superar as éticas do rosto e do acolhimento levinasianas, mas tenta pensar para além do axioma religioso que a sustenta, tanto na divinização do Outro quanto na questão do mal. Para ele a ética das verdades é "o princípio que permite a continuação de um processo da verdade - ou, para ser mais preciso e complexo, que acrescenta consistência à presença de alguém [some-one] na composição do sujeito provocado pelo processo dessa verdade"19. Para entendermos a composição desse conceito, será necessário verificarmos: a) quem é esse alguém; b) o que é o acontecimento; c) como se dá um processo de verdade; d) como isso se aproxima de uma ética.

Primeiramente, para ele, não se deve pensar em um sujeito em geral a partir do qual uma ética universalista, nos termos kantianos, se construa. Antes, a particularidade de certo tipo de animal, um alguém [some-one], em seus termos, pode criar a circunstância de ele se tornar o sujeito de uma ética. Esse animal que somos nós, em certa medida, é aquele que se depara com o acontecimento, e essa noção central para o argumento de Badiou é aquilo que possibilita ao animal tornar-se sujeito ${ }^{20}$. O acontecimento, para Badiou, é uma contingência histórica que se torna necessária afetando o múltiplo da vida. Ele é algo que "não pode ser reduzido ao simples título de 'é o que é"” ${ }^{21}$. Isto é, o acontecimento é uma irrupção imprevisível que não pode ser identificado ou compreendido propriamente. Em outras palavras "Acontecimentos são singularidades irredutíveis, o para-além-da-lei das situações" 22 .

O próximo passo no caminho de traçar uma ética das verdades é conceituar o que seja verdade. Diz Badiou: “Chamo 'verdade' (uma verdade) o real processo de fidelidade a um acontecimento: aquilo que essa fidelidade produz na situação" 23 . Há três importantes características desse conceito a serem ressaltadas: a) a singularidade da verdade; b) a situacionalidade da verdade; e c) o processo de fidelidade ao acontecimento. Primeiramente, devemos sublinhar que, para Badiou, não há a verdade enquanto tal, metafisicamente estabelecida e unívoca: há verdades. Isso justifica tanto a denominação de sua ética como ética das verdades, no plural, quanto, em sua definição de verdade, a clareza de que se trata de uma verdade. A situacionalidade está intimamente ligada à singularidade da verdade. Na medida em que uma verdade não é a verdade, segue-se que ela está sempre situada, isto é, está dependente de uma realidade histórica que lhe é exterior: o acontecimento. Todavia, não é meramente o acontecimento que cria a possibilidade de uma verdade, mas a fidelidade a ele. Antes, é a própria fidelidade que produz uma verdade na situação de um acontecimento. A verdade, nesse sentido, é o processo de manter-se coerente a um acontecimento, isto é, a própria fidelidade aos seus princípios.

Nesse sentido, a ética das verdades se estabelece enquanto coerência e fidelidade ao acontecimento que tornou um alguém em sujeito. Por isso, diferentemente de Levinas, a proposta de Badiou não é de uma ética generalista do Outro, mas uma reflexão situacionista e singular de fidelidade a uma verdade de um acontecimento. Por isso, também, a ética das verdades é formal, isto é, não apresenta um conteúdo específico de ação ou proibição, mas instaura uma forma que se adapta às mais diversas situações e acontecimentos. Ela responde à questão atual da pandemia na medida em que caracterizamos a experiência do isolamento como um acontecimento. Não apenas porque sem precedentes na contemporaneidade, mas

\footnotetext{
19 BADIOU, Ethics, 44 .

${ }^{20}$ Embora Badiou aprofunde com mais rigor e assertividade a constituição do sujeito em relação ao evento em Being and event, nos contentaremos com seus desdobramentos éticos aqui.

${ }^{21}$ BADIOU, Ethics, 41.

${ }^{22}$ BADIOU, Ethics, 44.

23 BADIOU, Ethics, 42. Grifos do autor.
} 
porque, de dentro dele, não podemos falar sobre o isolamento com total propriedade: não temos dimensão exata de suas consequências a médio e longo prazo tanto no campo da saúde quanto no campo político e social. Não sabemos expressar como serão nossas relações interpessoais pós-isolamento e nem se as haverá. Se consideramos, portanto, o isolamento por conta da pandemia como um acontecimento, a ética das verdades diz a seu respeito que devemos ser coerentes com seus princípios. Isto é, é-nos exigido que permaneçamos em casa, confinados e isolados - não apenas para nossa própria proteção, mas por segurança de outros sujeitos com quem possamos ter contato e que, nessa pandemia, também podem se incluir nessa perspectiva ética.

Aqui, a proposta de uma ética das verdades responde à problemática do isolamento de modo mais adequado porque, além da impossibilidade de uma ética do rosto, ela se mostra como uma ética do recolhimento. Ser coerente com o acontecimento pandêmico é recolher-se na própria habitação. A fidelidade ao isolamento, nesse caso, é essencial, é manter-se, também, fiel à verdade do acontecimento. Quando nem o rosto nem o acolhimento são possíveis, a ética situacionista das verdades pode postular o recolhimento como a prática que, no limite, pode levar de volta ao rosto, ao acolhimento e ao Outro.

A ética das verdades, por fim, implica uma ética do recolhimento na medida em que essa se coloca, para além de um imperativo moral, como uma necessidade biológica e sanitária. Nesse caso, ser fiel ao acontecimento pandêmico não apenas constitui um alguém sujeito, mas também mantém o sujeito saudável. Há, aqui, um movimento circular: na mesma medida em que a ética das verdades sustenta um recolhimento, o recolhimento fundamenta, biologicamente, a possibilidade de ação do sujeito no mundo. Ora, se não há ética sem alguém, o recolher é ato ético que sustenta qualquer ação ética nesse contexto inclusive o próprio recolhimento.

Isso implica, também, pensarmos que, em meio ao negacionismo do "apocalipse bolsonarista-evangélico" 24 , reafirmar os riscos bio e necropolíticos da pandemia seria outra forma de manter-se fiel à verdade do acontecimento, bem como preservar-se são e crítico, e como resistir aos impulsos de exceção dos Estados autoritários. Esses outros modos de fidelidade, quando comparados à ética do recolhimento, apesar de indicarem importantes tarefas para a manutenção da saúde e da dignidade da vida, são menos imediatos do que o recolher-se. Isso porque eles se dão por meio do recolhimento que, em todo caso, pressupõe uma habitação, mas, também, se instaura fora dela. Enquanto o recolhimento ético se coloca como princípio, há também um recolher-se fora da habitação, como gesto de resguardo e introspeç̧ão do toque e do contato. Aqui, mais do que mera polidez, o recolhimento possibilita o não contágio e o não cancelamento de futuro. Dessa forma, outras verdades éticas são possíveis e importantes para o tempo de pandemia, mas elas pressupõem, de alguma forma, o recolhimento.

\section{Considerações Finais}

Para Levinas, o recolhimento é o modo como o eu constitui a si mesmo. Mas o isolamento é insuficiente ao recolhimento: "o isolamento da casa não suscita magicamente, não provoca 'quimicamente' o recolhimento, a subjectividade humana” 25 . No momento do isolamento, invertem-se os papéis: o recolhimento se transforma no modo como o eu respeita o Outro em seu recolhimento necessário. A partir da ética das verdades, podemos

\footnotetext{
${ }^{24}$ DOS ANJOS; MOURA, O contágio infernal, 21.
}

${ }^{25}$ LEVINAS, Totalidade e infinito, 136. 
distorcer Levinas: o isolamento, hoje, torna-se não apenas recolhimento, mas também acolhimento da possibilidade da volta do rosto. Por isso a ética das verdades é, hoje, uma ética do recolhimento.

Portanto, buscamos aqui articular o diálogo entre as éticas propostas por E. Levinas e A. Badiou, tendo em mente nossa conjuntura global, em dois sentidos: primeiramente, apresentando as impossibilidades de uma ética do rosto e do acolhimento; depois demonstrando como a tese de uma ética das verdades, de Badiou, proporciona novas e úteis perspectivas sobre o isolamento social. Com esse diálogo, pretendemos salientar que, apesar de a ética levinasiana ser impossível no momento, não devemos cair em um niilismo pessimista. Antes, essa impossibilidade traz a chance da construção de uma nova ética formal que, a partir da vivência do acontecimento mesmo, nos permite construir uma conduta segura através da prática do recolhimento. O recolher-se não implica um fechamento definitivo em si mesmo, mas um isolamento social momentâneo para que o Outro e seu rosto sejam possíveis novamente. Em todo caso, mesmo diante das incertezas do futuro da pandemia, o recolhimento se mostra como uma ética adequada na medida em que mantém a possibilidade do Outro enquanto tal com o resguardo seguro do contato direto. Nesse sentido, a ética do recolhimento se sustenta como prática situacionista potente para um porvir incerto, justamente por suportar a tensão entre o Mesmo e o Outro sem reduzi-los nem arriscar perdê-los para a pandemia. Assim, a momentaneidade ou da situação não implica o fim da ética do recolhimento - apesar de seu caráter situacionista.

\section{Referências}

AGAMBEN, Giorgio. Distanziamento sociale. Quodlibet. Macerata, 6 abr. 2020. Disponível em: <https://www.quodlibet.it/giorgio-agamben-distanziamento-sociale>. Acesso em: 14 abr. 2020 .

BADIOU, Alain. Being and Event. New York: Continuum, 2005.

BADIOU, Alain. Ethics: An essay on the understanding of Evil. New York: Verso books, 2002.

DERRIDA, Jacques. Adeus a Emmanuel Levinas. São Paulo: Perspectiva, 2015.

DOS ANJOS, Fellipe; MOURA, João Luiz. O contágio infernal: o apocalipse bolsonaristaevangélico. São Paulo: Recriar, 2020.

HEIDEGGER, Martin. Que é isto, a filosofia? : Identidade e diferença. Petrópolis, RJ; São Paulo: Vozes; Duas Cidades, 2006.

LEVINAS, Emmanuel. Totalidade e Infinito. Lisboa: Edições 70, 1980.

LEVINAS, Emmanuel. Violência do rosto. São Paulo: Loyola, 2014.

NANCY, Jean Luc. Communovirus. Verso books. New York, 27 mar. 2020. Disponível em: <https://www.versobooks.com/blogs/4626-communovirus>. Acesso em: 14 abr. 2020. 